\title{
Free Spirits? The Academic on the Aeroplane
}

\section{Introduction}

'There is no more sombre enemy of good art than the pram in the hall.'

Cyril Connolly Enemies of Promise (1938)

Academics are often on the move, free spirits seemingly without cares'. Indeed, some are pretty indistinguishable from the business elite and a host of networked professionals, moving through airports with Blackberries and 4G laptops, rolling luggage confidently through customs in light and scrumple free travel clothing. Even though they might be employed in one place, they seem to work in many different places. Much of the time, they occupy what the anthropologist Marc Augé (1995) has called 'non-spaces' - the escalators, waiting rooms, hotels and transit systems that move people from here to there with as little friction as possible. In general, the more senior the academic, the more mobile they seem to be - gliding from Chicago to Kuala Lumpur, Naples to Sao Paulo. Checking in, checking out, going to gate. Not that mobility is itself a distinctive characteristic of academics. Bauman notes 'nowadays we are all on the move' (1998: 77, see also Urry 2006, Larsen 2006), though the 'we' here is a rather specific one. Two sorts of people are mobile, Bauman suggests, the precarious, transient and refugee who are compelled to move, or those with enough money who live in the Global North who choose to move. Setting aside package tourism to sunny beaches, the elite nomads from the travelling classes then include academics from the elite institutions of the global north. They have generous travel budgets, and something to say at the congresses, conferences and symposia that keep chain hotels profitable. This is a mobility which appears to be chosen, and is socially valued, not one which is forced and humiliating. It is a mobility which speaks with passport stamps, conversations about different airports and airlines, and the namedropping about where you are now and where you are going next.

The notion of the free spirit has been associated with intellectual work for a long time, but mainly in the sense of being free from political interference in the research process. However, this 'freedom from' did not always translate into high amounts of geographical mobility, but instead an insistence that the university needed to be defended from a possibly 
hostile environment. The walled monastery was a place which might need to be defended, but would not need to be left behind in order to do academic work. Few scholars before WWII travelled much, and even fewer moved permanently to different places. If they did so, they often travelled for political reasons, such as Jewish academics fleeing Nazi Germany or British scholars leaving their impression on academic life in the colonies. Nowadays, with relatively cheap and efficient global transport systems, the rise of the conference circuit and research travel budgets, the sense of 'freedom from' appears to have become a 'freedom to' pursue careers and academic capital from one international congress or top ranked institution to another. But if such movement is expected, and lack of movement treated with suspicion, then there is some coercion here too. The professional academic is not free to move where they want, or not to move at all, but softly compelled to move where they are expected to perform better. Indeed, their willingness to move is frequently being evaluated, and consequently so is their willingness to shrug off attachments and start packing.

In this reflective essay we will investigate the conditions of possibility of the super-mobile academic - the contemporary 'free spirit' - and relate them to the idea of the intellectual in the arts and social sciences ${ }^{2}$. Using our own experiences as a guide, we will look at how assumptions about the nature of the intellectual endeavour have become institutionalised and professionalised to fuel super-mobility. For us, this is a particularly interesting issue in the context of 'critical' academics in the social sciences, since that it what we know best, and perhaps where the accusations of a lack of reflexivity concerning these matters seems likely to slide into hypocrisy.

A dominant problem concerning theories of the intellectual (Rieff 1969, Boggs 2000) relates to their attachment or detachment from the world which they comment upon. As Hughes has elegantly put it, the European intellectual often assumes that they -

'... should survey with Olympian calm the social doings of his fellow men and, after a suitable parade of literary and historical learning, and a minimum of reflection on his presuppositions, come to certain rather majestic conclusions about what constituted the true, the beautiful and the good' (1967: 405)

It seems to us that aeroplanes and super-mobility have exacerbated this tendency, and even though we live in an age in which reflexivity is celebrated, there is little reflection on the 
presuppositions of weightlessness which are built into academic careers. These relate in part to environmental impact, rather nicely crystallised when over 10 thousand delegates jumped on planes, trains and automobiles to get to Chicago for the 2009 Academy of Management conference 'Green Management Matters' ${ }^{3}$. More importantly for our argument here though, there are also some fairly embodied questions about care and attachment, and the gender politics of an occupation which demands a regular detachment from the home as a condition of high performance. The idea of a spirit free from intellectual constraint appears to be related to the professional academic's freedom to be able to travel the world in search of ideas. Whilst having responsibilities is not the only reason for an inability to attend conferences - funding, geographical location and language issues are also relevant - in the this paper we will be concentrating on mundane matters of care. We think this is important because academic knowledge is shaped by the social relations it is embedded in, as well as those it is detached from. Does knowing then become detached also, and made into a commodity that is displayed by its very mobility? Does lack of connection to the ground, to any ground, become precisely the characteristic that defines this academic habitus and its products?

\section{The Conference}

An ubiquitous feature of academic life in the global north is the conference ${ }^{4}$. In his plea for conferences worthy of the name, André Spicer suggests that what actually happens usually disappoints.

'Indifferent food. Petty controversy of the latest theory. Many glasses of the local liquor. Extra-marital affairs. Verbal violence. Arrogant grunts. Closed circles. Dashed hopes. Petty promotionalism. Scholastic policing. Grinding headaches. Boredom. Body pain.' (2005: 21 )

Though Spicer holds out the possibility that conferences need not be like this, his piece is structured against their dull actuality. More recently, Bell and King have explored some of the ways in which conferences are often gendered sites for 'bodily dispositions of control and endurance' which count success as being able 'to win an argument, colonise a debate, claim an intellectual territory, or impose our logic on others' (2010: 429, 439). But neither Bell and King, or Spicer spend much time thinking about their most defining element, that conferences take place somewhere else. The latin root conferre suggests that they bring 
things together that were previously separated, whether ideas or people. They are periods outside the ordinary flow of events, held somewhere that most of the delegates don't usually go. Paradoxically, the coming together is only possible because individuals send themselves away. Conferences and meetings require travel, mobility, the negotiation of boundaries and borders and the consequent physical sequestration of the individual from the places where they usually sleep and eat (Urry 2006: 230 passim). In so doing, they also take the delegate away from the usual people that they care for and who care for them. Conferences break routines, and turn the world upside down. We use different money, eat different food, and sleep in someone else's bed.

There are many popular and professional accounts of why academics go to conferences, from secret affair to dull duty. In addition, we must not dismiss the idea that conferences might provide people with new ideas, either by giving feedback on papers, coming across work which stimulates thought and creativity, or making connections with others working on similar areas. The idea that the conference helps recharge the intellectual batteries after a long year of teaching is a common one too. But these sort of accounts are not the only ones. At the more careerist end academics might need to be seen by their peers and the powerful, to put some lines on a CV, to 'network' and so on. (Networking being a strategic form of social interaction in which success is measured by the potential value of the contacts made.) Hedonistic accounts might instead tend to focus on seeing friends, hotel swimming pools, tourism, heavy drinking or the taking of drugs. In his 1984 novel Small World, a romance of conferences and aeroplanes, David Lodge notes that conference attendees often behave as if they were teenagers - staying up too late, drinking too much and generally imagining that they are someone without attachments. Indeed, some academics go to conferences without going to a single paper, and an increasing number of conferences now market themselves as tourist experiences which can be paid for out of your employer's conference budget. Careerist and hedonistic accounts aren't mutually exclusive of course, because people can do one thing in the morning and something else in the afternoon. As Burrell suggests, commenting on the Academy of Management conference, carnivals and hiring fairs are not incommensurable places (1993: 74-5).

It is often unclear, to outsiders or participants, just what sort of work is being done at conferences but whatever the account, common to them all is the idea that there is an 
imperative to get away from home. It isn't expressed like that, but that's what it means, because academics rarely attend conferences with their children, spouses, elderly relatives or pets. They tend to leave their cares behind, in the hands of their partner or extended family. And, in case it needed saying, since the majority of care is still undertaken by women, it is easier for men to go to conferences. But whatever gender, and whatever dependents, an account is required to explain why it is necessary to leave someone else with the burden of care, and it is at this point that claims to be engaged in intellectual or professional labour become relevant to our argument.

\section{Professionalizing the Intellectuals}

Academic detachment from care and social obligations has a long history, is indeed one of the 'imprinting conditions' of academia. Eight hundred years ago, academics ${ }^{5}$ entered the world stage celibate (Denifle, 1885). Knowledge was considered a gift of God, hence its keepers had to follow the same rule as priests, and for the same reasons. One was purity before the altar, the other the ability to dedicate all one's time and effort to the holy cause and not be distracted by family and other allegiances. Furthermore, there were practical obstacles. One of the few female voices in $12^{\text {th }}$ century academia reminds her lover why it would not be a good idea to get married:

'What possible concord could there be between scholars and domestics, between authors and cradles, between books or tablets and distaffs, between the stylus or the pen and the spindle? What man, intent on his religious or philosophical meditations, can possibly endure the whining of children, the lullabies of the nurse seeking to quiet them, or the noisy to and fro of the servants? Who can endure the continual smell of soiled toddlers?' (Heloise quoted in Abelard, 1972)

The possibility of mobility was established quite early on in the history of the university. The most prestigious privilege granted to universities by Pope or Emperor was the ius ubique docendi, the right to teach everywhere (Rashdall, 1936). This meant that a university degree enabled a master to teach at any other university in Europe without having to pass further exams. This right defined universities vis-à-vis other (less prestigious) forms of education. Moreover, it set up the university as one of the first transnational occupations with 
academics supposedly belonging to an 'academic community' which was spread all over the continent.

We have, however, come some way from the late $12^{\text {th }}$ century, not only in terms of online bookings and funded academic exchange programmes. This is in part because of the professionalization of university work, and its connection with an institutional field which includes large and increasingly marketized universities, national funding and regulatory bodies, and international research funding agencies. In this context, it might be suggested that the idea of the intellectual is no longer relevant. However, we would argue that the super-mobility of the contemporary academic is actually an institutionalization of some of the assumptions built into the older idea of the intellectual. The person who wishes to live the life of the mind appears to be severing themselves from the attachments of the earth, and hence might be equally at home (or equally alienated) anywhere on the globe. That once they tended to sequester themselves in monastic universities, perhaps taking a walk to think at a regular time, merely indicates that spatial mobility is not functionally necessary to produce an account of being a free spirit. Freedom of the mind is not the same as the freedom of the body.

Metaphors of separation run through the often rather self-congratulatory accounts of intellectuals, almost always written by people who would rather like that label themselves. Talcott Parsons suggests that the intellectual is functionally semi-detached from societal obligations and primarily oriented to exploring and reproducing cultural systems (I969: 4). For Parsons, like so many other commentators on the question, the intellectual is necessarily some sort of outsider, a person distant from or standing above the mundane, like an absent minded professor who has his ${ }^{6}$ mind on higher things. Edward Shils makes a similar point about the detachment of the intellectual from their everyday world.

'There is in every society a minority of persons who, more than the ordinary run of their fellow men, are enquiring and desirous of being in frequent communion with symbols which are more general than their immediate concrete situations of everyday life, and remote in their reference in both time and space' (1969: 26)

For Shils this means that the intellectual must, in part, 'reject' the 'inherited set of values' which pertain in the society they live in (30). As he goes on to suggest, the ideal type of the only community that such people could hold allegiance to is really a global one, unhindered 
by 'boundaries of language, national pride and religious, political and ethical beliefs' (39). They are committed to the betterment of the practice and must hence cut across the sort of social and spatial distinctions that matter to other people. For Parsons and Shils, the intellectual is a social category, but one somehow underdetermined by the social. Other people are subjected to the rules of the central value system, but the intellectual somehow escapes.

For Karl Mannheim, this sort of magic trick won't really work. He treats the problem of the intellectual as part of his general sociology of knowledge ${ }^{7}$. In Ideology and Utopia $(1929 / 1960)$, he asserts that what counts as knowledge depends on social context, hence understanding modes of thought means understanding their social origins. Epistemology is social. This commitment involves a general suspicion of psychologistic or individualist accounts of thought.

'Only in quite a limited sense does the single individual create out of himself the mode of speech and of thought we attribute to him. He speaks the language of his group; he thinks in the manner his group thinks. He finds at his disposal only certain words and their meanings.' (Mannheim 1960: 2)

All people, then, are trapped within their own conceptual universes and their thought necessarily reflects its social origins. Like tastes for certain sorts of food or favourite songs, we are creatures of circumstance, broadly rehearsing the distinctions that we inherited from the people we have been close to. For Mannheim, the single individual does not think, rather 'he participates in thinking further what other men have thought before him' (op cit: 3). Thought is therefore ideological, not in the Marxist sense of class interests, but in the sense that it reflects the interests of the social group (or status position, or generation) who are doing the thinking.

This structuralist or institutionalist position on knowledge generation and analysis provides a powerful way to think about collective modes of thought. Yet it also contains a major performative difficulty. If all thought is socially determined, then this must also apply to the thoughts of the thinker. In other words, the category of 'the intellectual' who carries out the sociology of knowledge must also be socially determined, and therefore ideological in its turn. Mannheim's solution is to propose a category of the 'socially unattached' or 'freefloating' intelligentsia. 
'... unlike preceding cultures, intellectual activity is not carried on exclusively by a socially rigidly defined class, such as a priesthood, but rather by a social stratum which is to a large degree unattached to any social class and which is recruited from an increasingly inclusive area of social life' (Mannheim 1960: 139)

This group, because it lacks a clear social location, is capable of understanding society more clearly. This is a clever turn, since it translates a putative detachment from social contexts into a form of objectivity, or at least 'elevation' from the ideologies of the day. It also allows some intellectuals to promote the interests of socially under-privileged groups and aim their thought at future forms of social reconstruction. Hence, socially unattached intellectuals can evade the reproduction of the dominant ideology, and aim towards modes of thought which challenge the status quo. Yet the problem still remains. Even Mannheim's more reflexive account of the intellectual requires separation as its condition of possibility. The intellectual must be detached, because if they are too attached then they cannot be an intellectual. They must be cosmopolitans, not locals (Hannerz 1990).

Perhaps it is not surprising that as intellectual labour becomes professionalized, some of these assumptions are echoed in a new context. They might not be explicitly articulated, but they provide a context for understanding the professional academic who works for an organization which sells masters degrees for money and in which the Latin motto might date from the 1960s. So how does the professional differ from the intellectual? In the simplest of terms, the professional gives allegiance to a particular occupation, and their professionalism depends on how closely they adhere to the standards of that occupation as judged by others who practice it. Their 'duty' is hence to the occupation, and this may require sacrifices of time and effort which go beyond what could be specified in an employment contract. So professional academics might have to go to conferences because their professional practice demands it, and even if they might weakly protest about missing their home comforts, the congress in Hawaii still needs to be attended. Embedded within this sort of account is the idea of a chosen compulsion, a calling of some kind, which effaces any purely economic account of work and provides the worker with a certain nobility, even altruism, often termed a professional ethos (Freidson, 200I). Though there are plenty of more critical accounts of professionalization (Johnson 1972), our point here concerns the explicit claims made by those who wish to claim the higher rewards and status associated with professional labour. 
The idea of the intellectual is not that different in its claims that intellectual labour is somehow special, but tends to efface the organizational or occupational basis of that labour. Of course nowadays most intellectuals are also salaried professional employees, so we might expect a slippage between the two positions, but insofar as an academic identifies themselves as an intellectual they are claiming that they owe allegiance to ideas, to 'the work' itself. Intellectuals need to be outsiders in order to do what they have to do, they need to be spirit and not flesh, so the non-places of travel and conferences don't worry them at all. Indeed, they might relish the freedom that it offers to break free of the surly bonds of the everyday, and the suffocations of the quotidian. Our point is that the idea of the intellectual is a powerful one for imagining the demands and pleasures of academic life, and its insistence on mental detachment finds an echo in the physical detachment now demanded of the professional academic.

So if we are correct that the older idea of the intellectual has become professionalized and institutionalised in the figure of the globe trotting professor, then we have a kind of genealogy for the conference. It also encourages us to focus on how such mobility is being encouraged and audited. Like the employees of many large and complex organizations, the activities of professional academics are being shaped by a managerial logic which is not particularly concerned with 'spirits' and 'communities', but with output. If mobility is part of the academic life, the argument goes, well, then let's document it, count it (more is always better) and turn it into a performance criterion. Academic mobility has been institutionalised, and this has had consequences for the way academics work, the way they organise their communities, and perhaps even the way they develop ideas.

\section{Institutionalizing Mobility}

We have argued that what the idea of the intellectual allows academics to do is to produce an account of their principled detachment from forms of care in order to serve higher duties. The professional academic inherits this account, and it means that the imperatives of dependents can be more easily shrugged off because they conflict with professional responsibilities and/or the commitments required by a life of the mind. According to this account, the pram in the hall and the insistent demands of the domestic simply don't allow 
for the cosmopolitan detachment required for a dedication to research. Yet this isn't merely a matter of a personal dynamic of guilt and evasion, as if we were simply finger pointing at bad people, because these assumptions are also increasingly built into the structures of academic careers and university decision making.

Attendance at international conferences is almost always assumed to be a positive for $\mathrm{CVs}$, such that the lack of such attendance would require an explanation. Indeed, Bourdieu, in his study of academics, uses conference attendance as a proxy for 'scientific power and prestige' (1988: 46, 235, 24I). One of the authors has personal experience of these issues being raised in promotion documentation, and implicitly in a job interview as well. The frequency of international travel then becomes a sort of proxy for dedication to the social role, as well as a way of collecting the usual forms of social capital which might be deployed as referee statements, co-authored publications, invitations to speak at other universities and so on. An explanation which makes reference to caring responsibilities which prevent such attendance merely ends up suggesting that other aspects of a life are as important as the professional duties, which in turn throws into doubt the wholeheartedness of a commitment to these duties in the first place.

Questions of mobility are not limited to conferences however. Job applicants may well be sifted on the basis of the quality of the institutions where they have studied or worked, regardless of where they were brought up or have dependents. Being geographically mobile hence assists career mobility, and someone who is not prepared to or can't move hence suffers if they are not lucky enough to be based near an institution rated in the top rank. Many funding institutions, most notably the European Union, evaluate applicants' research records by counting the number of host institutions they have worked at, or more explicitly make the quality of the host institution part of the application itself. In the latter case, an application may fail if the quality of the host institution is not considered good enough, even though the researchers themselves might have perfectly good track records. This indicates an explicit assumption about researchers' ability and willingness to work at any place in the world, for the single reason that this is 'the best' place to conduct their research. Such an assumption clearly ignores any social responsibilities researchers may have and articulates them as detached monads. They are 'free spirits' in two senses. First, they are free in the sense of 'free from' social ties and responsibilities that might make them stay in one 
location. Secondly, they can be imagined as disembodied spirits without any needs or tethers apart from cognitive stimulation through an 'upward' career trajectory.

Crucially, the production of this autonomous individual is an institutional matter, because the success or failure of such a performance will be evaluated through committees which make decisions about jobs, promotions, grants and so on. If the candidate shows that they are a free spirit by showing little attachment to place or persons, they are more likely to be offered the opportunity to further demonstrate that lack of attachment. Paradoxically, the less local loyalty and solidarity they show, the better their prospects will be. Given that we now have pretty good means of electronic communication which eradicates distance, this insistence on a spatial change of workplace, whether a new job at regular intervals or a life of conferencing, is rather curious and needs some explanation. Most of the outputs from research in the arts and social sciences can be found in books and journals which are the same in Harvard and Delhi as they are in Oxford and Sydney. Most teaching and administration requires that people are in the same rooms on a regular basis. There appears to be no obvious technical reason why super-mobility is necessary to do the work of an academic, so the explanation for the free spirit on an aeroplane might be assumed to be a set of cultural assumptions which have become institutionalised in the universities of the global north.

The idea of institutionalizing mobility suggests that institution-building is at work here too, with all the political and ideological struggles that usually accompany that process (Friedland and Alford, 199I, Rao et al., 2000, Zilber, 2002). Institutions, according to Bourdieu (1990), are founded on social distinctions and seek to veil the distinctions they are founded on. In the context of universities, it seems that the distinction between the priest, pure in heart and body, officiating at the altar of Knowledge, and the laymen getting their hands and bodies dirty in the world is still in place, no matter how secularised universities have become. What is more, it is still enforced in personnel selection procedures and academic reputation mechanisms and successfully creates the subjects it intends to. The medieval intellectual has become the rootless academic.

The process also creates new features of academia precisely by producing an increasingly homogeneous intellectual environment. The continuous repetition of words like 
'international', 'global' and 'world' in the titles of conferences hides the fact that these events, be they in Greece or Massachusetts, have largely become occasions that celebrate one single academic culture: the Anglo-American one. While European conference proceedings up to the 1980s still testify to the fact that conferences were held in multiple languages with each presenter talking in her native tongue (or at least a language close to it), today's events are standardised, even up to the English section titles a paper has to contain. The very requirement to understand several languages in order to be considered an international scholar - see how Weber, Durkheim or Parsons discuss foreign works that they have read in the original - has been smoothed away by super-mobility, a condition that is only possible if you can be sure to find the same abroad as you would have at home: chain ideas for chain hotels. A distinction is created between those who have learned to express their ideas in English - or, shall we say, have learned to produce ideas that fit the English style of argument - and those who don't, and the latter will find it difficult to thrive in the 'international' academic circuit. Like its globalized economic counterpart, academia has not become richer and more varied but more streamlined. Mobility, it seems, both produces and is produced by a certain sort of sameness, and means that what you find when you get off the plane is increasingly similar to that which you left (Urry 2006). The more conferences there are, the less need there is for conferences.

At the same time, this superficial internationalism has not been able to lay to rest the ghosts of a parochialism which masquerades as inclusiveness. As Bourdieu (1999:220) observes,

'Intellectual life, like all other social spaces, is a home to nationalism and imperialism, and intellectuals, like everyone else, constantly peddle prejudices, stereotypes, received ideas, and hastily simplistic representations...'

In part, this is because the celebration of institutionalised mobility very often fails to provide the time and space for collective or individual thought. For the reasons discussed already, academics need to go to conferences and conference organizers need academics to pay and present. This means that most of the delegates will be presenting, as a condition of their funding from their employers, which in turn means that conferences almost always grow in size and provide less and less congenial arrangements for sustained discussion. It is normal now that a presentation be completed in fifteen or twenty minutes, and that an overspill of delegates who don't even get their fifteen minutes of fame be catered for with poster sessions. So too do the large professional conferences run multiple tracks, effectively 
guaranteeing that the less well known, or those presenting on heterodox topics, will have an embarrassingly small audience. For the presenter, it is then virtually impossible to say anything much to an audience which will almost certainly not have read anything in advance. Papers hence become brief, and bland, simply to ensure their digestibility in such inhospitable contexts. And that is just as well, because given the necessity to attend a lot of conferences and to present a paper there to get your expenses reimbursed; most delegates probably don't have a lot of groundbreaking findings or arguments to report anyway. If one were to design an event which minimised the possibilities of sustained and concentrated attention on a particular topic, the large multi-stream academic conference would be it.

Yet this doesn't mean that conferences are inconsequential, because they act as 'fieldconfiguring events' (Lampel and Meyer, 2008) flagging new trends and directions concerning research topics, framing issues and alternatives for discussion, and electing and presenting the key people at the centre of a field. It is an occasion where everybody, but most notably the good and great of the field, can reassure one another of their importance and belonging (Bell and King 2010). Urry notes in a similar vein that conferences are aristocratic rather than egalitarian undertakings that give to the rich (in network capital) and take from the poor (2006: 23I). In this sense, what happens alongside the conference is often just as important as what is said in the sessions. The most important events usually happen outside of the streams. While the delegates rush to the free finger food buffet, the journal editors, chairs of professional associations and publishers go for lunch on expenses.

As one might expect, money, too, plays a role. Organising conferences has become a business providing hotels and airlines with hundreds of thousands of customers as well as universities and professional associations with a sizeable extra income. The fact that the Academy of Management is able to organise their annual conference only in a few cities big enough to house and cater for 10,000 delegates is just one example of the staggering proportions of the size of the business involved. Professional conference organisers charge a fee to arrange such complex events, and the ensuing dramatic rise in conference fees certainly excludes those from different geographical or institutional locations. These event management organisations, perhaps initially growing in response to the conference circuit, now also push the process ahead themselves by facilitating ever bigger meetings where ever more money can be made. 
Simultaneously, universities themselves now market their ability to cater for large conferences. Campus universities in particular have unused bed spaces during vacations, as well as the usual range of seminar rooms, lecture theatres and places to sell delegates food and drink. For many such institutions, the burgeoning conference market provided a stream of income which they were very pleased to develop. The conference website of the University of Warwick, one of the leading UK conference universities, advertises I200 available bedrooms (which includes three conference hotels), and suggests that it hosts 200 thousand delegates a year and turns over $£ 22$ million $^{8}$. In larger cities, the development of clusters of conference hotels - almost always international chains with hundreds of bedrooms and lots of meeting space - has allowed for super-sized events such as those held by US professional associations each year. As well as contributing to the profitability of the groups that own Hilton, Crowne Plaza, Sheraton, Marriott, Sheraton, Holiday Inn and so on, city tourism offices actively work to encourage large conferences on the assumption that the spending on transport, hospitality and tourism will produce benefit in terms of economic multipliers and place marketing.

In summary, it seems clear that a wide variety of interests have come together to institutionalise the contemporary super-mobile academic. University managers and grant awarding bodies have made such mobility into a measurable quality for the purposes of recruitment, promotion and decisions on grant funding. University finance officers have been encouraged to turn their own universities into conference parks, partly in order to pay for the increasing conference expenses of their own academics. And the whole process has been assisted by specialist conference organizers, city marketing teams and international hotel chains, as well as the relative decline in the costs of air travel. The idea of the unattached intellectual is now embedded deep in these institutional relations but it has real effects, such that any young academic would be well advised to plan their super-mobile conference strategy as part of their career planning. Now it might be that this is a relatively innocuous matter, a source of cultural irritation and excess carbon release but nothing more serious than that. However, we wish to suggest that there are some broader issues at stake here too, and we will describe them in terms of the sorts of attitudes that are cultivated by detachment. 


\section{The Politics of Attachment and Detachment}

We have tried to show how one aspect of the intellectual's detachment, mobility, has been professionalized and institutionalised. Still, the question remains: Is the detached intellectual the better intellectual? If so, the ease of adaptation to being alien, the sort of casual fluidity that allows you to join groups easily, and not be the sad one standing on their own, could be taken as a measure of your skills in moving within this milieu. Crying, phoning home too often, leaving early, on the other hand, could be interpreted as signs of weakness (Bell and King 2010). A certain sort of insouciant cosmopolitanism of the 'if it's Friday I must be in Belgium' variety then becomes the sort of attitude which is encouraged if you rarely stay anywhere for too long. Theoretically, the idea of multiple weak ties and 'network capital' become terms which can valorise such global mobilities and communication systems (Larsen 2006). Konrad describes this ideal type cosmopolitan in very positive terms.

'We may describe as transnational those intellectuals who are at home in the cultures of other peoples as well as their own. They keep track of what is happening in various places. They have special ties to those countries where they have lived, they have friends all over the world, they hop across the sea to discuss something with their colleagues; they fly to visit one another as easily as their counterparts two hundred years ago rode over to the next town to exchange ideas.' (in Hannerz 1990: 244)

But does the intellectual have to be physically detached in order to do their work, floating rather than moored? It is a romantic view, and images of intense figures on mountain tops come to mind, but for rather more sedentary inhabitants of the contemporary university it might be that detachment from social location is actually not an everyday experience. The word 'intellectual' somehow validates certain sorts of behaviours and beliefs. It is, in other words, a claim about identity which is predicated on an idea of difference, and on a certain moral hierarchy (Parker 2000). The self-styled 'outsider' is a social location too, however hard it might be denied, and hence subject to the charge that the nomadic hero of the account is representing no interests but their own.

We agree with Mannheim that thinking is a social endeavour and thoughts are reflections of a person's social circumstances. This would make the thinking of a person with social responsibilities necessarily different to the thinking of a person without - not better or worse, but different. In an ideal world, these differences would not matter as both types of 
people would have their chance to voice their thoughts with the same authority. In this world, as we have argued, the dice seems to be loaded against professional academics with attachments. If intellectuals indeed reflect their social contexts, could it be that the emphasis on disembodied and displaced cognition has an elective affinity with the neo-liberal celebration of individuality, career and competition? Further, what are the extra-academic consequences of the demand for mobility?

The most obvious consequence relates to the gender politics of caring, which we have already alluded to above. Forty percent of all female academics in Germany born after 1965 are childless (Statistisches Bundesamt, 2005), surely not entirely because they hate children or can't conceive. As Zoe Williams noted recently, young female researchers are simply assumed to be mobile during the very years in which they are making decisions about children, yet ironically the only funding body which pays for childcare is the skincare company L'Oréal, through its science fellowships (201 I: 16). Simply put, if super-mobility is a condition of the job, but if women tend to take on the larger burden of caring responsibilities, then the demand to show evidence of mobility amounts to indirect gender discrimination. Even if we bracket the gender questions here, and insist that men as well as women can use the crèche (if available) at a conference, it still means that anyone attached to a particular locality for whatever reason will find it difficult to fulfil an increasingly explicit demand in this particular career.

Yet this is not simply an argument about discrimination - whether against women, carers, people who get travel sick, or just don't like leaving home. It seems to us that there are some more fundamental questions raised here too, and they relate to the nature of the knowing that is likely to be produced by the detached and super-mobile academic. A great deal of work on ethics now begins with the assumption that proximity and corporeality are conditions which shape our responses to others (Hancock 2008). This has been expressed in a wide variety of ways. Adam Smith's notion of 'sympathy' in his 1759 Theory of Moral Sentiments is an useful place to begin, suggesting as it does a physical reaction to the sufferings of others which is the basis of a moral response, but it is in twentieth century phenomenology where this form of thought really begins to flourish. For Maurice MerleauPonty, the body become central to accounts of what it means for humans to respond to one another. In Phenomenology of Perception (1945/1962) Merleau-Ponty makes our necessary 
embodiment into a condition of being human, and hence of the very ground of ethics and politics. This is echoed in the work of Emmanuel Levinas, in whose Totality and Infinity (1961/1999) corporeality and proximity become the 'first philosophy' which provides the ground for an unconditional response to 'the face' of the other. The relationality implicit in embodied responses to the other is then taken up in a host of feminist writings. To take just a few examples. Carol Gilligan's In a Different Voice (1982) proposed an 'ethics of care' to replace ideas of ethical development that relied primarily on accounts of cognition and rule following. More recently, Rosalyn Diprose has been putting forward a corporeal ethics based on generosity to the bodies of others $(1994,2002)$, and Margrit Shildrick and colleagues have been employing poststructural thought to think through an ethics of the body (Shildrick and Mykitivk 2005).

Our intention here is not to adjudicate between these differing versions of an embodied and relational ethics, but simply to note that they all rest on an implicitly social epistemology. That is to say that our orientations to others are shaped by our ways of being in the world with others. The sort of phenomenology which drives these contemporary forms of thinking suggests that ethics is not solely a calculation which happens in the head, but reflects our embodied locations, and the bodies we are surrounded by. We are what we do, and who we are with. The fact that these arguments have had particular resonances for feminists underscores that the idea that questions of care, generosity and relationality can be understood as deriving from the body, but also being located within a social context which tends to efface such understandings in favour of a disembodied conception of organization and rationality. An ethics of the body is often marginalised by institutions which demand that bodies are placed at their disposal, and that the comportment and disposition of human resources is a strategic and not an ethical question.

At its most minimal, our assertion is simply that there is a relation between a form of life and a form of thought. Despite his attempt to claim that 'free-floating' intellectuals are different, Mannheim would be unlikely to disagree with the broad outlines of this sort of argument, and it also fits well with the rather institutionalist way in which we have approached the question of the contemporary university and its super-mobile employee. What we are adding here is the idea that the disembodiment of the employee is likely to lead to disembodied thinking and acting - thinking which is not likely to focus on immediate 
and intimate questions of care, generosity and relationality. Instead we are likely to find forms of thought and actions which place a premium on the problems already established by universities as institutions - gap spotting, abstracted empiricism and the generation of widely disseminated theoretical implications. These are the forms of frictionless thought that are encouraged by the academy, and that academics can package easily and take on aeroplanes, publish in journals and get grants to work on. Accounts of local or parochial responsibilities, of 'sticky' encounters with the world, and of specific forms of care and engagement are less likely to travel well. Whilst we acknowledge that social ties can involve complex networks, technologies and mobility systems (Urry 2006, Larsen 2006) they do not efface the practical importance of proximity for care. It is difficult to look after elderly parents, children or neighbours by email.

It is a small step from ethics to politics, and indeed the same license for elective irresponsibility that applies to the professional academic seems to work well for their political engagement too. This is a particular difficulty for those who claim to be 'critical', since they are in some sense committed to forms of social change and in greatest danger of hypocrisy in this regard (Parker and Thomas 201I). We do not want to rehearse the theory-practice gap here but to point to the touristic attitude (in Bauman's sense) of the mobile intellectual towards political issues on the communal, national or international level (Dunne et al 2008) It might be imagined that academics, especially those who study management and economy, could contribute a lot to a world of staggering economic inequality, and facing huge ideological schisms. However, it seems that the convenient excuse of Weber's value-free science (Wertfreiheit der Wissenschaft) is all too often used to disguise actual detachment as dispassionate and careful analysis. In any case, the argument from Weber doesn't really hold. First, because Weber would never deny an academic's right to point out facts and thus combat popular misunderstandings (see in a similar vein, Bourdieu, 1999). Second, because while attacking the professorial habit of 'preaching [...] in the so-called objective, uncontrollable, undisputed silence of the lecture theatre, carefully protected by the state from every form of refutation' (Weber, 1988:492), Weber explicitly concedes the right of every academic to use the same channels of political engagement that are open to every citizen (Weber, 1988:493). Hence, Weber, rather than abstaining from political engagement, expects his colleagues to participate in political discussions, but not in a location where their authority prevents any critical discussion. This is the problem for any 
academic work which claims to be 'critical', and wishes to change the shape of the world. Moving outside the space of the conference and its associated circuits of mobility is thus a necessity for such engagement, whilst staying within it almost certainly guarantees that the only people who will hear you are the fellow inhabitants of the seminar room.

The medieval popes, who originally granted the ius ubique docendi mentioned above, were keen to create a body of able minds dedicated to nothing more than an idea because these useful men generated 'applicable' knowledge (for example, arguments justifying certain dogmas), and it was at the discretion of the Pope to apply it. The dream of the powerful is a world in which all their functionaries are detached, and the contemporary professionalization and institutionalization of the white collar academic as putatively free spirit makes this easier to engineer (Mills 195I). What began as a necessary defence of thinking against the interferences of the world has become a glass bead game with little or no relevance for those who are not schooled in its mysteries. It is a game played in the nonspaces of conferences across the world, and which is institutionally required for the professional academic to advance in their careers. Indeed, such mobility appears to be increasingly central to the trans-national business class more generally, as well as elites in a variety of domains for whom the first class lounges in airports have become familiar (Sklair 200I, Urry 2007). For academics, and perhaps others, this very requirement for supermobility further ensures that players do not bring their most corporeal attachments with them, hence ensuring that those who get on aeroplanes are free not to speak of things that they care about, or free not to care about them when they are at conferences. Or perhaps, dazzled by the joys of being super-mobile and obeying the demands of their institutions, they come to believe that professional intellectuals should float free from the world as a condition of their being intellectuals at all.

\section{References}

Abelard, P. 1972. Historia Calamitatum. The Story of My Misfortunes [Online]. New York: MacMillan. Available: http://www.fordham.edu/halsall/basis/abelard-histcal.html

Augé, M (1995) Non-Places: An Introduction to an Anthropology of Supermodernity. London: Verso.

Bauman, Z (1998) Globalization: The Human Consequences. Cambridge: Polity. 
Bauman, Z. 1995. Legislators and Interpreters, Cambridge, Polity Press.

Bell, E and King, D (2010) 'The Elephant in the Room’ Management Learning 4I/4: 429-442.

Boggs, C (2000) 'Intellectuals'. In G Browning, A Halcli and F Webster (eds) Understanding Contemporary Society: Theories of the Present. London: Sage, 296-3II.

Bourdieu (1998) Homo Academicus. Cambridge: Polity.

Bourdieu, P. 1990. The Logic of Practice, Stanford, Stanford University Press.

Bourdieu, P. 1999. The Social Conditions of the International Circulation of Ideas. In: Shusterman, R. (ed.) Bourdieu. A Critical Reader. Oxford: Blackwell.

Burrell, G (1993) 'Eco and the Bunnymen'. In J Hassard and M Parker (eds) Postmodernism and Organizations. London: Sage, 7I-82.

Denifle, H. 1885. Die Universitäten des Mittelalters bis 1400, Berlin, Weidmannsche Buchhandlung.

Diprose, R (1994) The Bodies of Women: Ethics, Embodiment and Sexual Difference. London: Routledge.

Diprose, R (2002) Corporeal Generosity. Albany, NY: SUNY Press.

Dunne, S, Harney, S and Parker, M (2008) 'The Responsibilities of Management Intellectuals: A Survey' Organization 15/2: 27I-282.

Freidson, E. 200I. Professionalism. The Third Logic, Cambridge, Polity Press.

Friedland, R. \& Alford, R. 199I. Bringing Society Back In: Symbols, Practices, and Institutional Contradictions. In: Dimaggio, P. \& Powell, W. (eds.) The New Institutionalism in Organizational Analysis. Chicago: University of Chicago Press.

Gilligan, C (1982) In a Different Voice. Cambridge, MA: Harvard University Press.

Hancock, P (2008) 'Embodied Generosity and an Ethics of Organization' Organization Studies 29/I0: I357-I373.

Hannerz, U (1990) 'Cosmopolitans and Locals in World Culture' Theory, Culture and Society 7: $237-251$.

Hughes, H S (1967) Consciousness and Society. London: MacGibbon \& Kee.

Johnson, T (1972) Professions and Power. London: Macmillan.

Lampel, J. \& Meyer, A. 2008. Introduction. Journal of Management Studies, 45, 1025-1035.

Larsen, J, Axhausen, K and Urry, J (2006) 'Geographies of Social Networks: Meetings, Travel and Communications' Mobilities I/2: 26I-283.

Version 08/07/2014, Page 20 
Legoff, J. 1986. Die Intellektuellen im Mittelalter.

Levinas, E (1999) Totality and Infinity. Pittsburgh, PA: Duquesne University Press.

Lodge, D (1984) Small World: An Academic Romance. London: Secker and Warburg.

Mannheim, K (1960) Ideology and Utopia. London: Routledge and Kegan Paul.

Merleau-Ponty, M (1962) Phenomenology of Perception. London: Routledge and Kegan Paul.

Mills, C (195I) White Collar. New York: Oxford University Press.

Parker, M (2000) Organizational Culture and Identity. London: Sage.

Parker, M (2002) "'The Romance of Lonely Dissent": Intellectuals, Professionals and the McUniversity' In M Dent and S Whitehead (eds) Managing Professional Identities. London: Routledge, I38-156.

Parker, M and Thomas, R (20II) 'What is a Critical Journal?' Organization I8/4: 4I9-427.

Parsons, T (1969) '’The Intellectual”: A Social Role Category'. In Rieff, P (ed) On Intellectuals. New York: Doubleday, 3-24.

Rao, H., Morrill, C. \& Zald, M. 2000. Power Plays. Resarch in Organizational Behavior, 22, 237$28 \mathrm{I}$.

Rashdall, H. 1936. The Universities of Europe in the Middle Ages, Oxford, Clarendon Press.

Rieff, P (ed) (1969) On Intellectuals. New York: Doubleday.

Sklair, L (200I) The Transnational Capitalist Class. Oxford: Blackwell.

Shildrick, M and Mykitivk, R (eds) (2005) Ethics of the Body. Boston, MA: MIT Press.

Shils, E (I 969) 'The Intellectuals and the Powers'. In Rieff, P (ed) On Intellectuals. New York: Doubleday, 25-48.

Spicer, A (2005) 'Conferences'. In C Jones and D O'Doherty (eds) Organize! Manifestos for the Business School of Tomorrow. Finland: Dvalin, 2I-27.

Statistisches Bundesamt 2005. Mikrozensus. Wiesbaden.

Urry, J. (2007). Mobilities. Cambridge: Polity Press.

Weber, M. 1988. Der Sinn der "Wertfreiheit" der soziologischen und ökonomischen Wissenschaften. In: Weber, M. (ed.) Gesammelte Aufsätze zur Wissenschaftslehre. Tübingen: J.C.B. Mohr. 
Williams, Z (20II) 'You don't need a beard to bring alive the surface of Mars' Guardian 23rd July: I6-I7.

Zilber, T. 2002. Institutionalization as an Interplay Between Actions, Meanings, and Actors: The Case of a Rape Crisis Center in Israel. Academy of Management Journal, 45, 234-254.

\footnotetext{
I Thanks to the referees for this journal, as well as Peter Armstrong, Gibson Burrell, Karen Dale and Steve Dunne for their comments on an earlier version of the paper.

${ }^{2}$ Our claims are made about the broad area of arts and social sciences, and not science and medicine because we know less about the latter. However, we would be surprised if there aren't similarities.

${ }^{3}$ Including one of the authors. We are not claiming to be external to these processes.

${ }^{4}$ Though our focus here is conferences as the most prestigious and visible feature of mobile academic life, we might add external examining, seminars, $\mathrm{PhD}$ examining, course validations, visiting appointments, field trips and a variety of other tasks that take academics away from their homes.

${ }^{5}$ The rise, and self-expression, of the intellectual is often dated into the $18^{\text {th }}$ century (for example, Bauman, 1995). If this were correct, academics would have been professionals long before they became intellectuals. We do not subscribe to this chronology and propose to view, with Le Goff (1986) the early university masters as intellectuals as well. As their identity was based on the idea that reason could act as an arbiter between different viewpoints, we detect the beginning of the idea of intellectual detachment at that time.

${ }^{6}$ Gender intentional.

${ }^{7}$ Parts of the section on Mannheim are based on Parker (2002).

${ }^{8}$ www2.warwick.ac.uk/conferences, accessed 20/7/II
} 